\title{
ENTRE A CASA, A RUA E A ESCOLA: O QUE O MENINO VIU? ITINERÁRIOS DE UMA CRIANÇA EM SÃO PAULO
}

\author{
Marcia Aparecida Gobbi ${ }^{1}$
}

\author{
PONTO DE PARTIDA
}

\begin{abstract}
Agora é suficiente que se diga simplesmente que constitui um ritual muito importante e altamente sombrio a primeira vez que alguém (menino ou menina) vai para a rua sozinho, seguindo sua própria cabeça, acompanhando apenas as pessoas de sua idade, estando "naturalmente" sujeito a todos os perigos e tentações que recheiam aquele espaço.

É como se estivéssemos pondo em contato não só dois espaços, mas também dois tipos de temporalidade.
\end{abstract}

(Roberto DaMatta, p.55, 1997)

Sabemos que as crianças ocupam um lugar singular nos espaços urbanos. Contudo, o que conhecemos sobre as experiencias sociais e culturais de meninas e meninos nos espaços públicos a partir de seus pontos de vista, sobretudo quando têm até seis anos de idade? Em que medida o itinerário feito a pé e diariamente por um menino com cinco anos pode nos dar pistas para pensar o urbano, em especial a cidade de São Paulo? Essas perguntas se encontram no conjunto de questionamentos que temos feito em grupo de pesquisas ao longo de alguns anos e servem como provocadoras de reflexões que relacionam temáticas voltadas à infância, cidade e representações imagéticas criadas por crianças desde bebês. Imagens essas tão fecundas e propulsoras de debates e construção de práticas sociais e representações.

Somos constituídos a partir de histórias contadas em inúmeras versões majoritariamente adultas, e não raro, masculinas e brancas, o que vem sendo questionado em diferentes pesquisas. Contudo, compreender narrativas que considerem as crianças - a partir delas mesmas - com bem pouca idade e moradoras de diferentes espaços, entre eles a rua, os bairros periféricos, cortiços, as ocupações urbanas, os assentamentos e condomínios tem nos inquietado. Inquietações que têm alimentado pesquisas. Ainda há muito o que conhecer e histórias a contar considerando a perspectiva infantil. As crianças, sobretudo as de bem pouca idade, são raramente citadas a partir

\footnotetext{
${ }^{1}$ Bacharel e licenciada em Ciências Sociais - USP. Mestre e doutora em educação - UNICAMP. professora doutora, da FEUSP. mgobbi@usp.br
} 
delas mesmas o que nos deixa lacunas quanto ao conhecimento sobre os modos de viver, morar e construir cidades pelas e com as crianças e as representações criadas por elas acerca desses espaços e condições de vida. Encontramos permanentemente o ponto de vista e as práticas adultas como reguladoras das relações sociais - únicas vozes legitimas e legitimadas - e aos adultos como sujeitos presentes nos espaços públicos, estes historicamente construídos por eles, deixando-nos sempre perguntas sobre como seria se os mesmos fossem criados também como obras das crianças. A ausência de crianças, em especial com menos de seis anos de idade, em espaços públicos, acentuada em alguns bairros, faz com que muitos sintam-se surpreendidos com sua presença quando não estão se dirigindo à escola ou demais ambientes fechados, supostamente mais seguros, locais onde comumente as encontramos.

O artigo Entre a casa, a rua e a escola: o que o menino viu? Itinerário urbano de uma criança em São Paulo resulta de investigações que procuram formas de apreensão das crianças sobre a cidade, sobre suas experiencias e experimentos, invenções, modos de vida e que buscam saber como interagem com às transformações espaciais, que tantas vezes, as deixam alijadas de processos e relações sociais. Nesse ensaio optou-se por um recorte bastante delineado a partir de um conjunto de fotografias criado por um menino frequentador de Escola Municipal de Educação Infantil, doravante denominada EMEI. Procura-se, a partir delas, promover reflexões sobre o tema infância e o urbano. Sem dar respostas definitivas, considera-se um duplo aspecto: como temática ampla e complexa que ora vem ganhando espaço em debates e pesquisas acadêmicas e, o que tem nos ocupado em maior proporção, as imagens que podem representar aspectos relacionados ao viver em distintos espaços da cidade, nesse texto especialmente de São Paulo, numa investigação que implica metodologias de pesquisas criadas para compreender questões do urbano a partir do ponto de vista das crianças, incluindo as de bem pouca idade. Sublinha-se aqui que não se trata de alcançar a questão a partir de um fragmento isolado, qual seja, pequena quantidade de imagens fotográficas. As fotografias aqui apresentadas, embora provoquem boas reflexões, não são compreendidas como algo inteligível em si mesmo. Procura-se, dentro dos limites de um ensaio, o estabelecimento de relações com os contextos histórico, social e cultural em que foram elaboradas, bem como conjuga-las às falas daquele que as elaborou. Há que considerar os elementos que envolvem o criador fotógrafo, com suas histórias de vida e condições de criação, somadas ao processo envolvendo contextos social, histórico, cultural em que a imagem foi elaborada, e ainda, o objeto, aqui a fotografia e seu idioma próprio, tantas vezes desafiador para nossa compreensão, reiterando-se ainda que o entendimento concernente à imagem sofre alterações de acordo com o percurso formativo, história de vida, classe social, gênero, etnia daquele que a vê. 
Assim, considerando estudos sociológicos como base para compreensão da temática e a importância das imagens aqui apresentadas, pretende-se contribuir com estudos sociais da infância e estes em relação à cidade e imagens elaboradas pelas crianças. O recorte etário se justifica pelo desejo/interesse em perscrutar e conhecer pontos de vista e os universos retratados por essas crianças na primeira infância, o que ainda é escasso, ao mesmo tempo em que nos instiga a refletir sobre prováveis e diferentes percepções e relações com o urbano. Uma de nossas questões para esse ensaio é: quando de posse de câmeras fotográficas o que as crianças registram? $\mathrm{O}$ que nos apresentam quando miram as cidades? Para onde estão focando e o que podemos ver a partir delas e com elas? Subjazem algumas outras questões. Se, como supomos aqui, as crianças estão apartadas de uma vida social em praças, ruas, parques cada vez mais raros, ou mais recentemente, em franco processo de privatização e desmonte, as crianças em idade menor que seis anos sequer estão contempladas, seja pela inexistência de equipamentos próprios à suas brincadeiras e corpos e formas de ação social, seja pela regulação que se dá pelo medo da convivência com o outro em espaços públicos que se tornam grandes reguladores sociais da e na infância. Para as crianças, seu funcionamento é ainda mais eficaz e perverso por somar-se à compreensão adulta de que as crianças são incapazes de defesa o que reforça a ideia de mantê-las em ambientes fechados. Casas, edifícios ou, por que não, os shoppings e suas áreas de atendimento personalizado e homogêneo, simulador de paz e igualdade, vão conformando as crianças a consumidores iniciantes. Importante para a reprodução do capitalismo, porém, perverso, cuja autonomia passa a ser confundida com descaso das famílias ou outros responsáveis. Essa relação com o espaço está presente na construção de modos de ver a cidade pelas crianças? Constam nas temáticas abordadas por elas?

Contornamos a região da Bela Vista, zona central da cidade, respondendo a uma provocação deixada pelas fotografias apresentadas por um de seus moradores. Uma sequência de fotos, aqui parcialmente reproduzida, levou-me a vagar imagética e presencialmente pelas ruas registradas pela câmera transportando-me a diferentes tempos e espaços que procurarei apresentar dentro dos limites desse ensaio. Pretende-se explorar exclusivamente o universo investigado e fotografado por Zé Carlos $^{2}$, frequentador de uma EMEI situada no bairro da Consolação e morador de uma das inúmeras casas multifamiliares da cidade, ou como denominação usada por ele, cortiço ${ }^{3}$, situado no bairro da Bela Vista, zona central de São Paulo.

Qual ponto de vista deve-se adotar para entender o ponto de vista das crianças? Essa pergunta orientou a pesquisa e implica a escolha de caminhos que privilegiem as crianças tendo

\footnotetext{
${ }^{2}$ Zé Carlos é nome fictício.
} 
como objetivo conhecer as representações espaciais criadas e marcadas nas fotografias, bem como, aquelas vividas por elas, desde bem pouca idade. O tratamento é dado pela convicção de que as crianças são seres inventivos, criativos e capazes, sendo o que é entendido em estudos sociológicos como agentes que negociam e criam novos modos de ser e viver a cidade, por que não, também afetando as relações citadinas.

Tomo de empréstimo a reflexão feita por Castro (2007, pág, 03): estaríamos, todos nós adultos, sequestrando o direito da criança de falar por si mesma, ao nos colocar na posição de representá-la e de lutar por seus interesses frente à sociedade mais ampla? Aqui, ressaltamos que não se trata de falar por elas, mas contar com metodologias que escutem e considerem suas vozes e modos de ver e registrar o visto. São vários os estudos que têm colaborado para refletirmos sobre a especificidade das investigações sobre e com as crianças, tais como Gobbi (2011,2017), Delgado \& Muller (2011), Farias, Naiade, Muller (2017), Corsaro (2011), Hirschfeld (2016) em busca de metodologias de pesquisa que têm as crianças como agentes no processo de pesquisa com o intuito de revelar seus pontos de vista e que nos inspiram. A perspectiva metodológica guarda suas especificidades principalmente quando empreendida em investigações que procuram considerar crianças com bem pouca idade, o que tem exigido de pesquisadores/as que construam caminhos próprios, sob pena de que, no desejo de conhecer as crianças e diante de certa incapacidade de compreendê-las em sua inteireza e singularidade, abafemos suas vozes e demais capacidades de expressão que podem ser reconhecidas como fontes a informar sobre elas mesmas ou o entorno vivido e experienciado cotidianamente.

No projeto de pesquisa que, entre outras reflexões, deu origem a esse ensaio, vigorava a proposta de que as crianças fotografassem ou desenhassem ao longo de diferentes itinerários entre eles o que compreende casa-escola-casa parando, olhando e decidindo se queriam ou não captar imageticamente o objeto visto em diferentes contextos fotografáveis e desenháveis. Várias escolhas estavam envolvidas pressupondo a autonomia das crianças que definiriam o que fotografar ou desenhar, ao mesmo tempo em que comporiam seus cenários. Outra possibilidade era elaborar as imagens em casa o que e se quisessem a partir de uma combinação coletiva, entre todas as crianças. Para alguns isso resultou a criação de desenhos coletivos, feitos em família o que provocou novas reflexões sobre metodologias a serem empregadas e como lidar com os resultados imprevistos, ao mesmo tempo em que promoveu o retorno do questionamento sobre as relações hierarquizadas entre adultos e crianças e a confiança estabelecida entre eles naquilo que remete o ato de desenhar. Recolheram, e porque não, recriaram aspectos do cotidiano vivido e os registraram em fotografias 
digitais e/ou desenhos. Ambos se apresentam como um elemento bom para pensar sobre as cidades e o urbano, enfatizando aqui a criação de fotografias.

Quando coadunadas aos contextos social e histórico de criação as fotografias aqui apresentadas permitiram perceber o bairro, e com isso a própria cidade, como locais de disputas e superação das mesmas e também de encontros, diferenças, mediações, convivência. Ao considerar algumas das imagens em consonância com matérias jornalísticas publicadas no primeiro semestre de 2017, percebe-se disputas num território contestado pela administração municipal em jogo com proprietários de terrenos e edificações, numa cidade negociada constantemente em continua demonstração de concepções diversas quanto a gestão de espaços públicos que não os prevê como direito de todos. O direito à cidade que implica discutir a propriedade privada e sua exacerbação presente nas relações construtoras do urbano, está afastado daqueles que nele habitam. Como afirma Harvey (2014) a urbanização é um fenômeno de classe social, assim sendo, devemos questionar sobre as crianças, e entre elas aquelas de bem pouca idade, como agentes nesse processo, ao mesmo tempo que ocultadas por ele, já que sua produção não é diretamente lucrativa. Excetua-se momentos ou lugares em que sua presença pode gerar lucros, tais como, em eventos comerciais em que ferozmente o desejo pelo consumo é gerado entre a criançada.

Quais usos da cidade estão disponíveis às crianças e quais aqueles construídos ou inventados por elas? O que elas definiriam como fotografável e em que medida essa definição pode levar a conhecer aspectos até então desconhecidos da cidade? Suas fotos serviriam como fontes a documentar a cidade? Contam histórias, ou uma história de cidade a partir da infância? Tais questões orientavam o modo de ver as imagens e mais, a forma como pretendia conduzir os caminhos da investigação. Porém, as fotografias de Zé Carlos chamaram a atenção por suas escolhas recorrentes: os grafites. Elas foram reproduzidas em parte nesse ensaio depois de uma necessária escolha para publicação no âmbito de uma revista acadêmica. Ao colocar as fotos lado a lado se reconhece o itinerário percorrido por Zé Carlos. Interessada em identificar o percurso e em confrontar seu olhar com os objetos fotografados, reconstitui pessoalmente o caminho por ele trilhado diariamente, seguindo as imagens que me foram exibidas, por ele, na escola logo após têlas registrado. Uma das perguntas boas a se fazer para uma imagem fotográfica é como elas nos provocam a pensar, Samain (2012). Aqui não apenas instigaram a pensar como a continuar a ver convocada por elas a percorrer e refazer caminhos na busca pela forma como um menino enxerga a cidade e não a enxergar exatamente como ele, já que não sou mais criança e vivo outras condições sociais, etárias, culturais, econômicas. 
A fotografia foi eleita como como recurso para a pesquisa considerada como artefato de cultura que documenta, comporta-se como agente e representa certos aspectos concernentes aos modos de ver e estar em diferentes condições de vida em tempos e espaços distintos. Assim, as fotos-artefatos são importantes, tanto quanto são fundamentais as formulações que as rodeiam. As fotografias têm se mostrado como fundamentais para refletirmos sobre a cidade de São Paulo e suas representações. Condições de vida, modos de morar e viver, usos do espaço público, relações estabelecidas com o outro estão presentes nas imagens fotográficas com suas distintas gramáticas. Imagens que foram criadas e registradas pelo menino a partir do percurso sempre trilhado a pé e que o leva da escola até seu local de moradia. Defende-se aqui o andar a pé pela sua capacidade de provocar diferentes formas de ver, além de politicamente contrariar a prevalência do tempo do automóvel e suas lógicas. Esse ato vai nos permitindo ver exemplos representativos de aspectos do cotidiano nas periferias e regiões centrais e as possibilidades de usos da cidade em equipamentos públicos, ruas e praças. Andar a pé implica outro tempo para percorrer espaços o que invariavelmente leva a ver coisas que não seriam enxergadas ao fazer o mesmo itinerário em outros veículos. É possível apreender isso a partir das fotografias de Zé Carlos, que nos permite inferir sobre a cidade, ou uma pequena parte dela. Destaca-se aqui que seu retorno a pé até sua casa, para alguns, reforça a ideia de insegurança e exposição ao perigo, ainda mais na região em que se encontra como morador. O medo repõe o seu lugar e garante o aprendizado das normas necessárias para a vida em sociedade, como afirma Vladimir Safatle (2015) trata-se de uma forma de gestão social em que o medo ganha sua versão política e geradora de afetos que afastam da vida pública. Infelizmente, observamos que esse aprendizado é antecipado, cada vez mais, chegando ao berço.

\section{CHEIRO DE JAQUEIRA, BUZINAS E OUTROS}

Rua Consolação, nela está situada a EMEI frequentada por Zé Carlos, cuja jaqueira logo no portão de entrada confere, em determinadas estações do ano, um odor forte e meio adocicado à parte do quarteirão, chamando a atenção de quem passa por essa rua exigente de passos acelerados, naquilo que configura nosso imaginário citadino em que germinam ao mesmo tempo os conflitos, as diferenças, as relações. Não é sempre que temos jaqueiras ocupando partes do espaço urbano em regiões centrais, bem como a convivência-disputa entre sons de crianças e o transito intenso de automóveis. Datada dos anos 1950 e criada como Parque Infantil o espaço físico da EMEI é amplo e disputado numa região central valorizada economicamente. A cidade-negócio não descansa sua incessante busca por lucros nem mesmo quando estamos em espaços públicos como parques ou escolas. É dentro dela que procurava estar de corpo inteiro a escutar e observar as crianças. Imersa 
junto a tanque de areia, arvores, espaços para brincar e salas com poucas cadeiras e mesas. $\mathrm{O}$ proposital desalinho, contrariava o questionável modo escolar de arrumação de espaços e tempos. Os sons de falas, gritos, risadas, eventuais choros ocupavam, enriqueciam e compunham o ambiente ao mesmo tempo em que exigiam da pesquisadora bastante atenção. É possível afirmar que estava em campo e ele estava em mim como num mergulho no desejo de conhecer e se dar. Estar presente durante certo período em alguns espaços da EMEI foi uma opção e se mostrou como imprescindível para a composição da pesquisa. Troca de olhares, negociações, consentimentos, autorizações, conversas, informações compuseram a estada nas escolas de educação infantil pesquisadas ${ }^{4}$ e não podia deixar de ser assim na escola frequentada por Zé Carlos.

Do ponto de vista metodológico a caminhada foi adotada como recurso para captar imagens da cidade a partir do itinerário percorrido. Foram caminhadas guiadas pelas adultas envolvidas com a escola e pesquisadoras e outras caminhadas livres em que eu era guiada pelas crianças em lugares até então desconhecidos por mim. A proposta era deixar com eles a câmera fotográfica para que registrassem aspectos do cotidiano que julgassem oportunos, sendo eles o caminho de retorno à casa ou vinda à escola, junto de adultos ou sozinhos, a própria casa, parques, enfim, o que pretendessem e fosse possível.

Caminhar leva a descobertas e uma câmera na mão pode materializa-las no tempo e no corpo do caminhante, ao mesmo tempo em que, agentes que também são, podem construir a percepção de tempos e espaços. Frestas podem se abrir e se mostrar em contextos, por vezes, eclipsados que se encontram de modo material e imaterial, já que as imagens evocam diferentes relações. Torna-se possível observar o modo como são ocupadas as casas, os espaços públicos, as maneiras como lidamos, por vezes sem pensar, com o outro, seja ele o que ou quem for.

Os locais registrados durante o caminhar foram escolhidos pelas crianças de modo aleatório. Sem combinado prévio sobre o que fotografar e estando de posse da câmera por alguns dias, levavam-na para casa e a traziam de volta com muitos registros. Eis que muros, grafites e uma longa conversa da qual apresentarei apenas um excerto nos contam o que por vezes, não vemos mais, ou melhor, não mais enxergamos, compreendendo o enxergar como forma de conhecer de modo mais acurado algumas dimensões do cotidiano e perscrutá-lo, estranhá-lo.

Na EMEI tivemos várias incursões envolvendo a pesquisa, desde a ida ao cemitério da Consolação, supermercado, visita à feira e biblioteca. Vale ressaltar que se trata de práticas cotidianas entre as crianças nesse espaço tornado lugar da infância, atividades em que fui tentando

\footnotetext{
${ }^{4}$ Trata-se, como já mencionado de uma pesquisa maior da qual expõe-se aqui um recorte apenas.
} 
me encaixar ao longo da pesquisa. Todos os locais mencionados situam-se na região central da cidade. Interessa observar que a quase totalidade das crianças demonstrava domínio sobre o espaço, o que levou algumas delas a me conduzirem por ele sob a alegação de que eles conheciam onde iam e eu não. Tratava-se ali de compreensão clara da presença de uma estrangeira entre eles e elas, cuja gramática desse espaço lhe era desconhecida, e dá-lhe mãos que se ofertavam a mim como guias a conduzir por espaços desconhecidos. Em suas falas e propostas estavam explicitadas as relações de conhecimento travadas com e na cidade, em alguns casos até mesmo em cumprimentos dados a certos moradores de rua que pareciam frequentes por onde passávamos. Era perceptível a fala orgulhosa de si ao mostrarem autonomia que eu, a adulta, a seus olhos, não podia ter. Essas formas de conduzirem e serem orientados na rua faz perceber o aprendizado de outro tempo subversivo às égides do acelerado capital. Se a rua é esse espaço em que vigora um individualismo bastante negativo às relações, esse gesto das crianças compôs minha afirmação de que podemos compreender outras práticas sociais de caráter mais igualitário e democrático.

Os relógios do supermercado e do cemitério ali presentes nada mais eram que parte dos apetrechos de regulação social ainda não totalmente seguidos pela criançada, provocando a pensar em outras experiencias com o tempo no espaço com as crianças e delas que se compunham e se sobrepunham ao chamamento dos semáforos ou dos adultos e das adultas receosos de que o "pior" pudesse acontecer às crianças nessas vias públicas. A rua, esse espaço do medo e da segregação, da diferença e dos conflitos, da junção de pessoas e suas dispersões, do sagrado e do profano que, por vezes, se reúnem e se identificam, como em algumas festividades. Vale lembrar que a Consolação foi e ainda é palco de grandes manifestações sociais e que as mesmas cultivavam jeitos e modos de ver e estar nesse lugar da cidade de São Paulo. Retardar ou antecipar entrada ou saída das crianças era uma constante em $2013^{5}$ e anos seguintes quando tivemos uma profusão de movimentos sociais presentes em frente à EMEI mencionada. Isso dá tons para conversas, caminhadas que podem ser suspensas ou adensadas por transeuntes. Há inegavelmente um ato político nesse caminhar e na pesquisa enquanto isso ocorre, são práticas embebidas.

Investigar, estranhar, anotar. Entre os grandes desafios fica-nos a escolha sobre o que considerar durante e depois da pesquisa. Quais imagens devem ou podem ser apresentadas? Como organizar o material que compreenderá o texto? Posso comprometer as crianças com as escolhas feitas? Saberemos respeitar seus pontos de vista? E o que for escolhido apresentará as crianças, tal

\footnotetext{
${ }^{5}$ Refiro-me a movimentos sociais que ocuparam ruas, com centenas de milhares de pessoas, em vários estados e cidades do país reivindicando melhores condições de vida, inicialmente voltados à questão de mobilidade urbana e ajuste de preços das passagens de ônibus.
} 
como desejado no início da pesquisa? Essas questões ganham maior peso quando buscamos compreender as crianças às pesquisas. Discutimos conjuntamente sobre essas seleções e posterior redação do texto, no desejo de escrever com a criança e não somente sobre ela, ou, pelo menos com seu conhecimento e consentimento? Há uma faculdade criativa no percurso que compreende escrever um texto como bem sabemos. Esse processo pode ter seu início em campo, o caderno em que anotamos o que vemos e ouvimos traz uma escrita, por vezes imagens - até mesmo elaboradas pelos participantes.

O desenho aqui reproduzido foi elaborado e deixado em meu caderno de anotações em campo, numa folha solta, num lapso de tempo em que ele ficou esquecido nalgum lugar. Eu o recebo como presente e como fio a iniciar o enlace de um caminho a ser percorrido juntos. Sem o caráter mercantil, trata-se do presentear como troca, tal como acepção de Marcel Mauss, em que se misturam coisas e pessoas. Talvez uma provocação, uma chave a abrir diálogos. Optei por mostralo aqui como forma de registrar alguns momentos da estada com às crianças. Ressalto que esses aparentemente detalhes são fundamentais na composição de uma tessitura que está imbricada à pesquisa e vão dando seus tons, apontando caminhos, permitindo a aproximação e, quem sabe, vagarosamente se compondo como dicas auxiliares no processo de compreensão das questões concernentes aos meninos e meninas em distintos contextos.

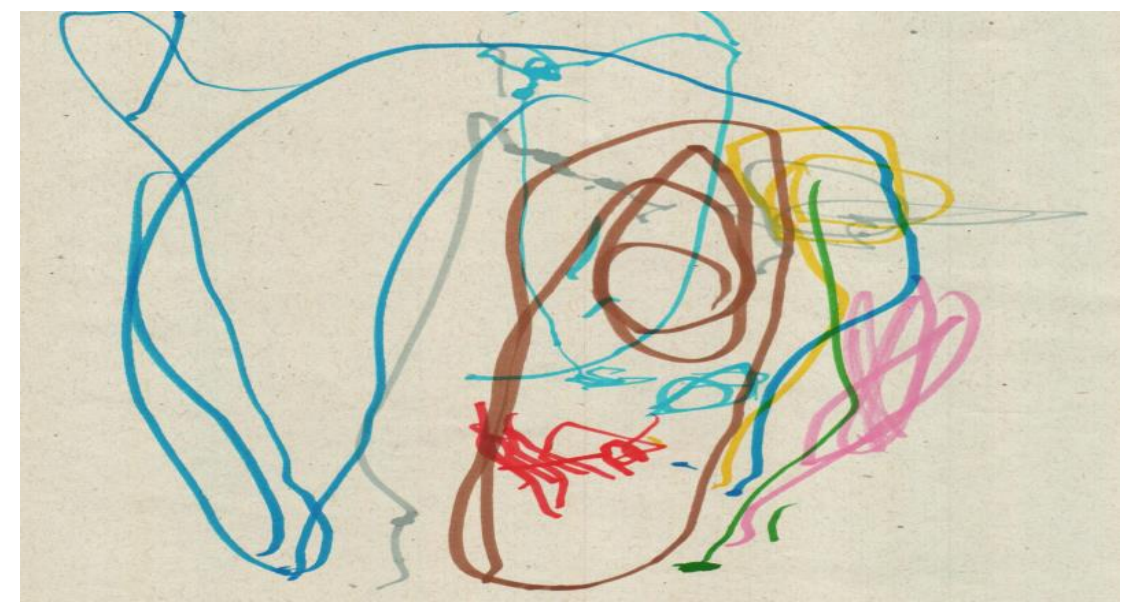

Reprodução de desenho feito por uma criança, não sei se menino ou menina, durante minha estada na EMEI.

Os desenhos deixados em meu caderno por algumas crianças, entre outras coisas, foram compondo o desenho da pesquisa. São como marcas de passagem a evidenciar o "estou aqui". Escuta atenta sobre o que elas contavam acerca da escola ou de seus bairros de origem foram compondo o tecido da pesquisa, a qual devo dizer, as vezes numa trama meio puidinha com gosto de "o que estou fazendo", em outros momentos, com linhas mais maduras e fortes, e ainda outros com sinais de certeza e desejo de apresentar texto a texto: imagético, escrito, inscrito nas relações e 
corpos envolvidos. Espero que esse tenha sentido ao outro que o lerá e que possa contribuir para aprofundamentos nos estudos sociais da infância em diálogo com investigações sobre a cidade e as imagens. Eis algumas das escolhas para compartir e provocar diálogos em duas cenas que dialogam.

\section{SOU TODA OUVIDOS: NO PRINCÍPIO FOI A CONVERSA}

Afinidade e confiança foram construídas vagarosamente entre mim e boa parte das crianças, assim avalio, passando a ser convidada e outras vezes guiada por elas em distintos contextos. Zé Carlos não se furtou a participar e, com isso, foi calmamente olhando, se aproximando até que numa manhã me chamou para conversar, me tirando do local mais movimentado em que eu estava, como a segredar uma história.

\section{Ei, professora posso contar uma coisa?}

Sim, claro.

Sabe, onde eu moro a mulher não deixa a gente falar alto e nem brincar. Ela fica brava.

Mas, quem é a mulher? É a mamãe?

Não, é a dona. Lá onde eu moro. Ela que cuida de lá.

E onde você mora? Lá. Tem a rua aqui da escola, tem a rua da feira, tem o parque e sabe já tá perto... É la no cortiço.

Cortiço?

É.

Sabe o que aconteceu lá?

Não, não sei.

Posso te contar?

Sim, se você quiser. Então vem cá.

Às vezes, fica uma polícia lá. Eles acham que a gente rouba coisas.

Eu já contei isso pros meus amigos daqui, né Pedro?

(que ouvia atento a história contada pelo amigo e confirmou o que dizia Zé Carlos)

A publicação desse trecho de nosso diálogo foi autorizada por Zé Carlos. Julguei necessário conversar sobre seu uso devido a algumas informações que pensava serem sigilosas, procurava ser coerente com minha postura junto às crianças guardando maior proximidade como participante da pesquisa que desse modo se fazia "com ele". Conhecer aspectos de sua vida, além de mobilizar meus interesses acadêmicos e de reconhecer que eles constroem modos de ver e se relacionar com o outro, estimulam pensamentos e considerações no âmbito político quanto à forma de tratamento voltado as crianças e jovens, formas precárias de moradia numa cidade em que vigora uma desigualdade estrutural. Interessa considerar que a mera chamada de atenção para me contar algo implica considerar que os espaços vão demonstrando suas variantes de significação social. Segundo apreendi o tanque de areia não cumpria a função de lugar onde se contam histórias mais densas. 
Espaço de brincadeiras de participação coletiva, contar o caso do irmão, ainda que já tornado público entre os demais colegas, reclamava um espaço mais privado, uma sala para onde fui levada e me fiz toda ouvidos para dar conta de atentar ao que me era dito. Essa é parte integrante da história de vida de Zé Carlos, semelhante à de outras tantas crianças paulistanas e brasileiras, mas que certamente contribui para a composição de seu processo de criação fotográfica.

Escolas municipais de educação infantil, local onde ouvi e registrei essa e outras falas, sempre me afetam. Atribuo esse sentido ao fato de ter sido professora de crianças, por opção, ao longo de muitos anos nessa rede pública o que me confere o desafio de "estranhar" esse pedaço que penso tanto conhecer, embora sempre com surpresas, e em que permaneço com muito prazer. Abalos alegres e constantes em alguém que insiste em retornar e reconhecer-se ou conhecer mais. Pensei de início que fossem segredos compartilhados por Zé Carlos somente comigo, o que, como se vê no final das anotações, não era, já que outras crianças já ouviram a história antes de mim. $\mathrm{O}$ que sei é que o sentido estava sendo explicitado e concomitantemente construído entre mim e as crianças, em especial, Zé Carlos. Estávamos em relação. Minhas expectativas quanto ao lugar ocupado pelo vinculo, informante e tantos outros importantes componentes desses estudos em campo, levaram-me a elaborar representações que poderiam atrapalhar a compreensão do que tinha sido narrado pelo menino, quase querendo validar a fala ao lhe conferir um status que não tinha. Possui outros, provocadores da urgente construção de escuta e sentidos atentos para aguçar a compreensão.

A criação de imagens resulta de longo processo de apreensão e elaboração do mundo, deste modo, temos que os idiomas contidos nas fotos redundam daqueles que as fizeram em continuo exercício que envolve reflexão e a soma de diferentes elementos estéticos, culturais, sociais, ideológicos. Assim sendo, considerar a foto e sua recepção, requer diferentes componentes, um deles refere-se a conhecer quem a produziu, o fotografo. Muitos seriam os destaques, porém, o que me interessa são aqueles que apontam para concepções de infância que poderiam passar ao largo de nossa escuta e tentativa de compreensão e que são esboçadas cotidianamente. Todo dia ela faz tudo sempre igual, como exposto pela letra da canção de Chico Buarque, e o silêncio que silencia ou cala as crianças, principalmente quando se trata de meninas e meninos pobres, num vagar impiedoso e traiçoeiro e que constrói seu lugar social como algo natural, intransponível e a ser tolerado.

Zé Carlos chama a atenção para a memória da cidade via cortiços que são formas de moradia do período de urbanização e industrialização da cidade de São Paulo, remontando ao século XIX. De caráter bastante precário reuniam múltiplas famílias, já que para essas não havia outra condição de moradia ou aluguel de casas devido aos altos valores cobrados. Atualmente, 
muitos deles concentram-se em grande número no bairro da Bela Vista. Hoje, segundo Kowarick (2013) eles não são reminiscências do passado, os preços pagos são altíssimos. Menos numerosos, ainda se oferecem como próximos aos locais de trabalho o que é avaliado como sedutor àqueles que moram neles. Muitos deles não aceitam a presença de crianças e não causa surpresa a fala de Zé Carlos ao afirmar a imposição de silêncio pela "mulher", possivelmente a responsável pela moradia cuja presença é porta-voz e garantia do cumprimento das regras impostas aos moradores. Não precisamos avançar muito com as reflexões para nos indagarmos sobre as condições de vida de uma criança nessas residências. Interessa apenas refletir, a partir da fala do Zé Carlos, que a subalternidade é construída nesses locais desde a infância. A fala do "polícia" narrada pelo menino demonstra a vagarosa construção do lugar de cada um em nossa sociedade, o que, infelizmente vem se acentuando por práticas como as mencionadas em que há um enquadramento dos jovens e um aprendizado da subalternidade, agentes que são isso não se dá em via de mão única. Creio que o mero ato de contar a história aos colegas e a mim já se constitui, sob certos aspectos, num princípio de rompimento com o silêncio. Kowarick (op.cit) ainda chamará a atenção para esses modos de vida que resultam em perda da dignidade e pergunta-se sobre a infância nessas condições em que vigora um ocultado pacto do silêncio. Que práticas sociais são cultivadas? Ou ainda, que formas de ver e registrar o que é visto são aprendidas? Elas estão presentes na composição das imagens? Afirma-se a construção das imagens em relação com a história de vida daquele que as compõem, o que justifica a apresentação de aspectos de sua fala que situa o fotógrafo social, econômica e culturalmente.

\section{TEMPO E ESPAÇO NO ANDAR A PÉ: ITINERÁRIO URBANO DE ZÉ CARLOS}

Todos os dias Zé Carlos volta caminhando para sua casa. Isso nos provoca a pensar sobre percursos feitos a pé por crianças com tão pouca idade na grande cidade: ele volta para sua casa, saindo de rua de ampla movimentação de automóveis, ostensiva presença de comércio, ocupações de moradias e culturais, como a já conhecida Casa Amarela ${ }^{6}$. Vale ressaltar questões de segurança tão presentes no conjunto de preocupações e justificativas para não ocuparmos os espaços públicos das grandes cidades. Ao envolver as crianças numa região central como a que estávamos implica pensar sobre processos históricos que as colocam como indefesas nesse mundo tido como conturbado e perigoso.

\footnotetext{
${ }^{6}$ A Casa Amarela, um casarão que data de 1920, tem se estabelecido como Quilombo Urbano em São Paulo, Quilombo Afroguarany Casa Amarela, e situa-se bem em frente à EMEI. Isso provoca a presença de algumas crianças em eventos propostos no local e recebem alguns artistas da casa na EMEI.
} 


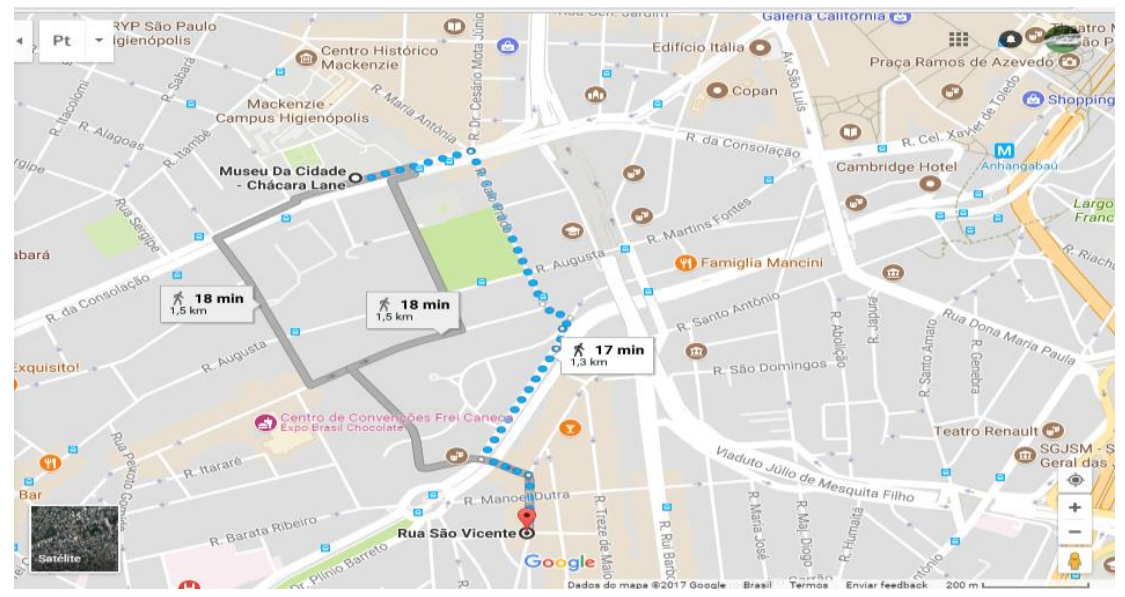

Google maps - consulta em 20/09/2017

A reprodução desse pequeno mapa com pontilhados em azul tem como objetivo apenas apresentar o itinerário percorrido por Zé Carlos diariamente. Ao observarmos o trajeto percebe-se que ele passa por regiões que têm sido postas constantemente nas mídias. Trata-se de áreas disputadas pelos interesses imobiliários representados por grandes empreiteiras e poder público. Temos o Parque Augusta, terreno de 24 mil metros disputados entre município e construtoras e que pode ser visualizado na cor verde num pequeno quadrado que se apresenta como grande área arborizada numa cidade acinzentada. Os 17 minutos a pé até as proximidades de sua residência o colocam lado-a-lado de uma história recente de conflitos pelo espaço urbano a ser negociado, ao mesmo tempo que lhe apresentam expoentes da arte urbana e da profunda desigualdade social que vivemos na cidade, como veremos adiante.

Seguimos guiados pelas fotografias no formato dado pelo Zé Carlos aos caminhos por onde passa diariamente:

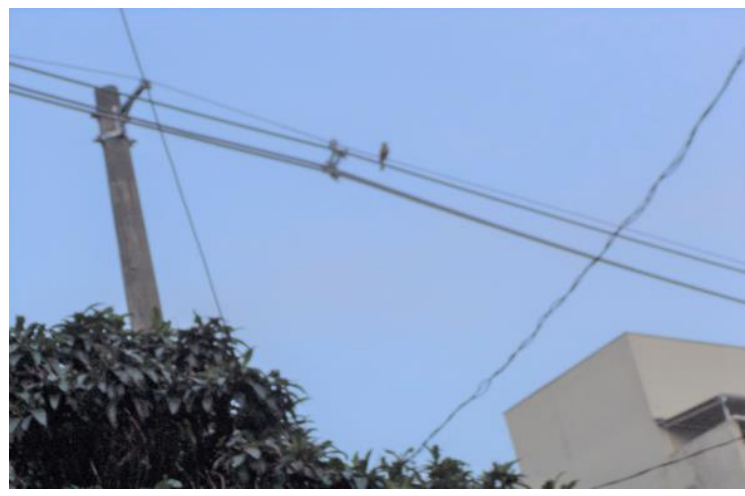




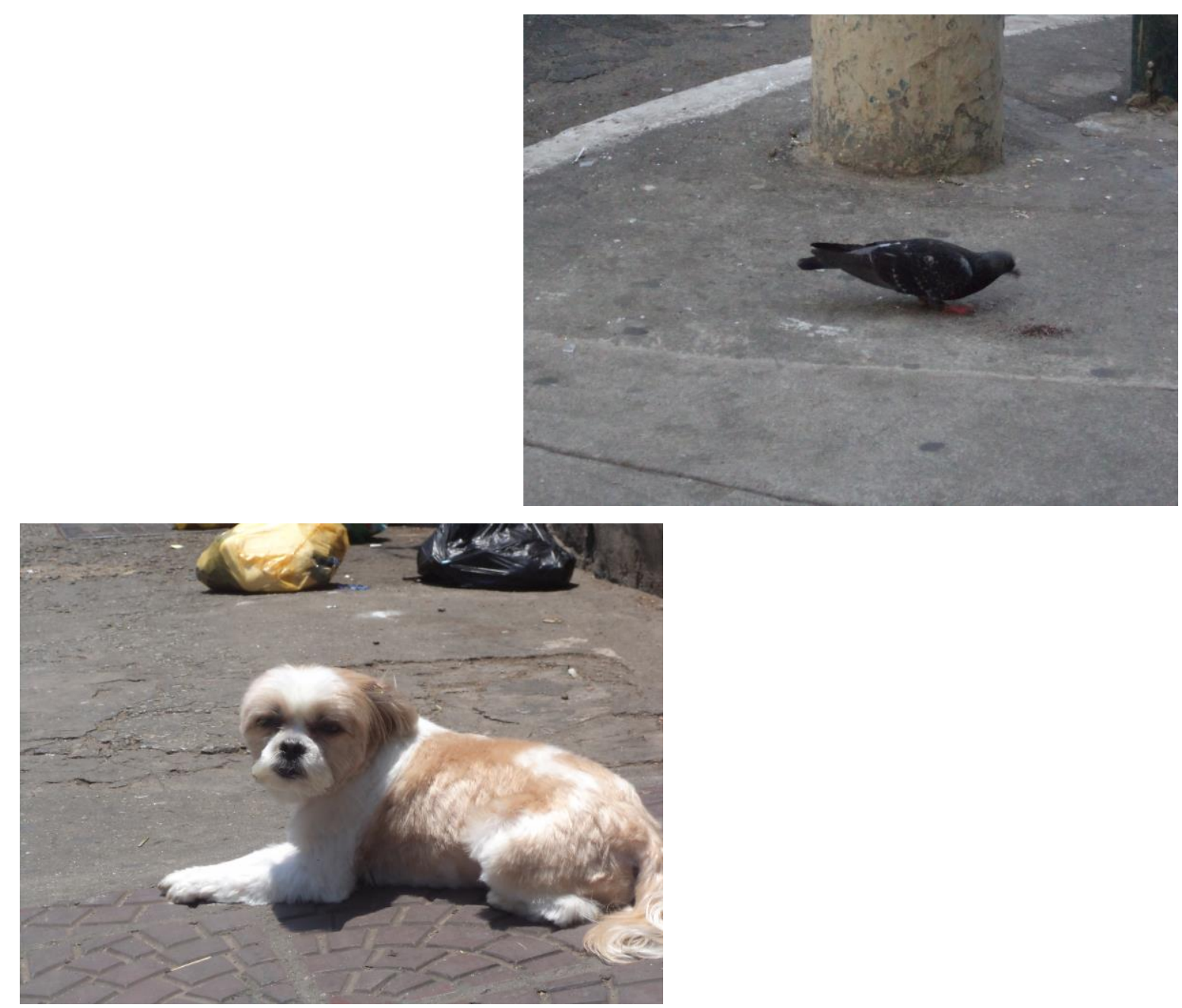

As fotografias são portadoras de pensamentos, como afirma Samain (2012) e além disso instigam e constroem pensamentos e modos de pensar e agir. Segundo Etienne Samain as fotografias veiculam figuras, mas muito mais, o pensamento daquele que a produziu e o de todos que olharam para a imagem. É memória de memórias (p, 23) assim, de acordo com o proposto, temos que as imagens aqui presentes ao se associarem nos trazem aspectos a ver e promovem outras ideias sobre o itinerário de Zé Carlos. Ao fazer parte de sua história nos aproxima dela e das contradições e diferenças presentes na cidade, como na fotografia do cachorro no primeiro plano em que ao fundo vê-se a presença de sacos de lixo no espaço público da calçada trazendo o indicio da confusão entre público e privado grande problema na paulistana cidade e, não só, da limpeza urbana e cuidados no tocante à população. Esferas pública e privada se confundem exemplificando o patrimonialismo tão presente em nossa constituição e, com isso, perceptível no trato dado às ruas e àqueles que nela transitam. Zé Carlos nos traz a imagem boa para pensarmos sobre essa relação em que lixo e espaço público demonstram convivência e disputa em descasos e usos do espaço. A vergonha da desordem e do sujo na rua deixa de ser nossa e passa a ser do Estado, DaMatta (1997) e Zé Carlos evoca essa compreensão na imagem registrada, se é o espaço do cidadão, da 
convivência torna-se o do confronto com a ausência de direitos, nesse caso, saneamento básico, limpeza pública. A casa, seu local de moradia revelado apenas em sua fala, não nos foi apresentada em fotos.

\section{Grafites de Zé Carlos X o cinza de São Paulo}
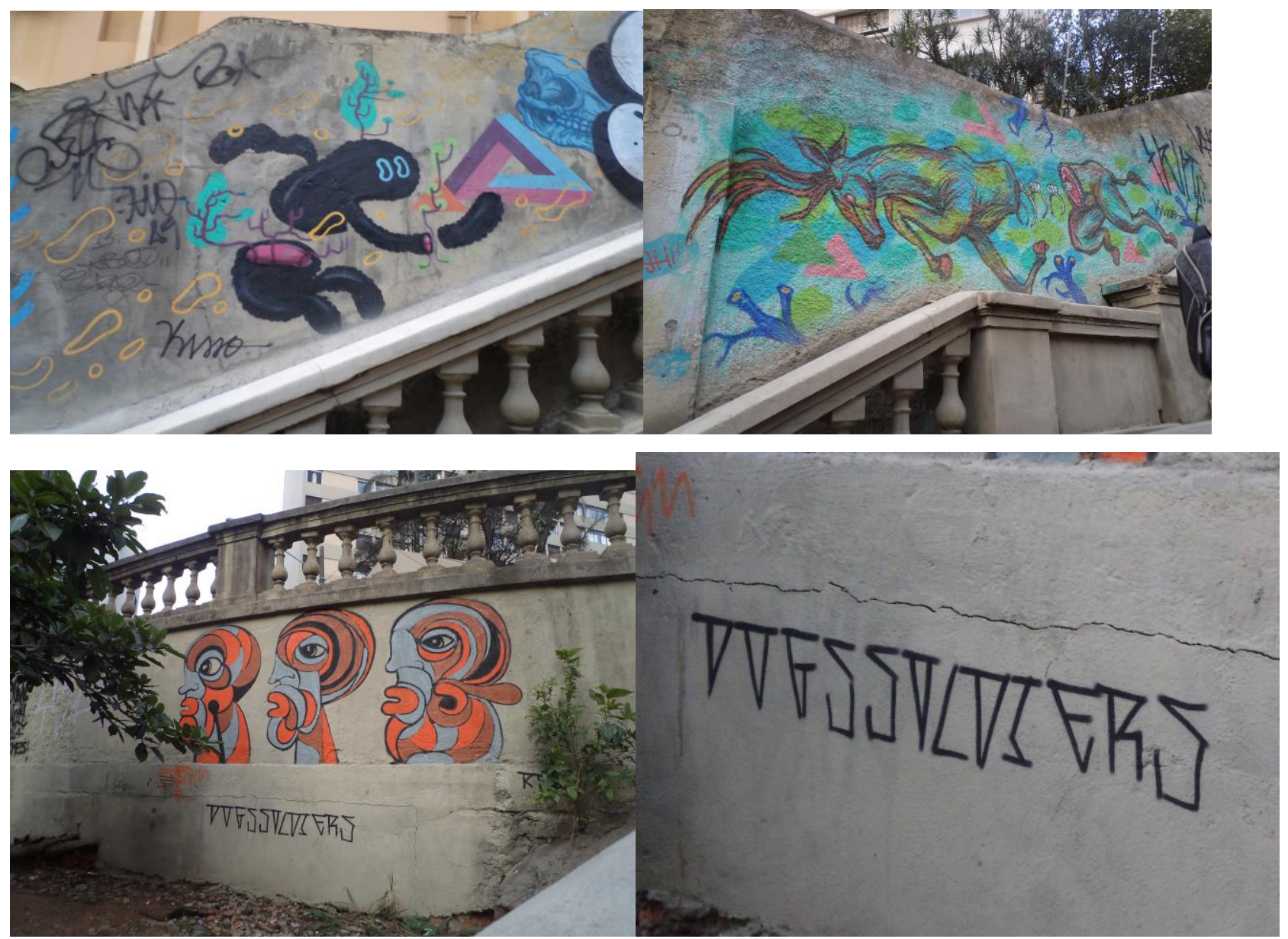

Entre 16 fotos contendo grafites escolhi somente 4 para apresentar nesse artigo por serem representativas da temática recorrente em todo conjunto. Trata-se de algo difícil, pois sabemos que a escolha é deixar ver aquilo que consentimos que seja visto, e, nesse caso, duplamente envolve a pesquisadora e Zé Carlos, esse último deixando uma escrita de história via suas criações imagéticas. Ainda que de modo incipiente percebe-se uma contribuição infantil para o conhecimento da recente história da cidade, já que inegavelmente constrói uma memória e traz índices bons sobre os quais refletir.

Poderíamos fazer referências à cidade grafite em que os artistas urbanos fazem uso dos muros como lugar de fortes expressões. Essas tão comuns em diferentes bairros traduzindo em parte aspectos da cidade de São Paulo e seu cotidiano. Muitas são as pesquisas que têm nos grafites suas temáticas para investigações artísticas e acadêmicas. Outros são os que procuram apagar tais 
manifestações acinzentando o já tão gris horizonte paulistano. Desde janeiro de 2017 vive-se sob o projeto político Cidade Linda, o que, ao contrário do que o nome diz, tem retirado o pouco de cor e de relações entre os transeuntes que rompiam com espaços sem vida, vozes e corpos na cidade. $\mathrm{O}$ projeto, de caráter higienista e segregador tem marcado a retirada da arte de rua alegando que se trata de limpeza e reorganização urbana demonstrando repúdio aos pichadores, grafiteiros e moradores de rua, especialmente com esses últimos acentuando o abismo social há tempos existente. Há um evidente confisco dos espaços públicos em São Paulo o que implica enclausuramento das pessoas. Triste e injusta maré cinza que deixa atônitos a muitos dos moradores e moradoras cujas relações com a cidade e memórias vão sendo apagadas junto com os traços nos muros.

Será que uma menina fotografaria grafites? Há um olhar fotográfico aprendido por meninas e outro por meninos? Embora esse ensaio não tenha dado centralidade a questões de gênero uma pergunta que pode ocorrer ao ver as imagens relaciona-se ao fato de terem sido produzidas por um menino. Não me demorarei nessa questão, contudo, não posso deixar de registrar como hipótese que temos diante de nossos olhos uma vista de cidade, não apenas por criança, mas por um menino, o que implica uma composição infanto-masculina de cidade o que resultaria em amostragem diferente. Aliás, esse mesmo espaço que cerceia a presença de crianças o faz de modo ainda mais contundente quando são meninas. A essas o espaço é ainda mais restrito ou apresentado como amedrontador. Entre centenas de fotografias criadas por meninas e meninos não temos grafites. Eles são encontrados unicamente no conjunto de Zé Carlos. Margeiam seu caminho junto a cães, pombos e fios elétricos expostos a conduzir um traçado nos céus, como linhas a colocarem margens às ruas. Há uma produção de sentidos via fotografia e imagem fotográfica e essa se dá com afirmações entre os sujeitos envolvidos no processo, deste modo, infere-se que se encontra marcas de gênero e etária nessa escolha e elaboração imagética. Há no grafite uma linguagem que se aproxima da criança? Percebe-se pelo conjunto e o que fora exposto aqui uma escolha, de caráter também subjetivo, daquilo que Zé Carlos queria expor, ou fazer com que o outro visse. Mostra o que consente que seja visto, como deixa claro em uma de nossas conversas em que ele, ao me entregar a câmera fotográfica, sinaliza para suas escolhas: deixei as mais bonitas e com isso coloca à tona seu gosto, em construção social.

Mas, há algo mais a destacar nesse curto espaço. Duas das fotografias deixam ver corrimões, o que se apresenta aqui como indicio a ser considerado e perseguido com curiosidade. Esta é a escadaria do Bixiga que data do final do século 19 e liga as ruas Treze de Maio e Rua dos Ingleses. Remonta a uma história referente ao processo de urbanização e declínio de grupos mais ricos e 
residentes em regiões centrais da cidade em que a Rua Treze de Maio abrigava população de exescravizados e seus familiares nascidos livres em convivência com uma elite paulistana moradora das imediações da Avenida Paulista. Ainda se vê alguns poucos sobrados altos e no alto da cidade. Lá funcionava um Clube de Golfe, cujas bolinhas ao caírem na região mais baixa provocavam uma relação nem tão tranquila, evidente de relações de classe presente no ato de as crianças pegarem as bolinhas para os jogadores do "alto". Ao observarmos ambas as fotografias e seus corrimãos podemos pensar na construção dos espaços da cidade que revelam a presença de diferentes temporalidades, e a escadaria com seus grafites nos permitem essa inferência e aprendizado colocado a lume pelas lentes de Zé Carlos. Diferentes tempos num mesmo espaço captados pelo menino. Passado e presente lado a lado nas imagens captadas fazendo ver ou provocando a pensar sobre onde estamos e o que construímos e nos constroem. Ainda seguindo acepções de Henri Lefebvre temos que Zé Carlos talvez tenha tomado o seu espaço vivido, representado por ele via inscrições/obras nas paredes sobre outra obra, a cidade propriamente dita em suas diferentes camadas.

Nesse artigo buscou-se apenas apresentar algumas ideias provocadoras de pensamentos sobre o urbano a partir de um local bastante específico. A cidade é lugar de experiencia e o é para as crianças, desde que tenham oportunidades para tal. Lugar que se quer do medo, com profundas desigualdades sociais e econômicas, pode ser obra criativa a ser inventada e descoberta por todos.

\section{CONSIDERAÇÕES FINAIS: QUANDO VER TORNA-SE ATO DE CRIAR PAISAGENS E CRIA-LAS EM NÓS}

La ciudad se ha tornado hostil para sus propios ciudadanos: es peligrosa, agresiva, está privada de solidaridad, de espíritu acogedor. Señor de la ciudad es ahora el automóvil, que produce peligro, contaminación acústica y atmosférica, vibraciones, ocupación del espacio público. Las calles son peligrosas, pero es en esta ciudad donde debemos vivir, y especialmente el que tiene hijos siente la necesidad y la urgencia de una solución.

Francesco Tonucci

Infância e cidade têm se apresentado como temas cuja relação se mostra bastante fecunda e cada vez mais necessária a compor estudos sociais da infância, em especial com forte caráter sociológico e antropológico. Moradia, mobilidade urbana, brincadeira, relações e práticas sociais, diferença, habitar são temáticas importantes quando nos debruçamos sobre a infância, em especial com as crianças de pouca idade, que sempre foram e ainda são alijadas das discussões sobre 
cidades. Ainda temos conhecimento lacunar sobre meninas e meninos nos espaços urbanos e como os representam, como vivem, como moram, como circulam, e se o fazem pelas ruas e praças das metrópoles, em que condições isso se dá. Satisfazemo-nos ao registrar com naturalidade a presença das crianças em espaços que mais nos lembram confinamentos que antecipam a normatização adulta. Como afirma Tonucci a cidade hostil, tida como violenta - o que tantas vezes, infelizmente, corresponde à realidade - urge ser conhecida e conquistada também pelas crianças e, quem sabe, modificada com elas. Seu potencial inventivo não pode passar ao largo de projeções que buscam alterações e a criação de espaços de relação não baseados no consumo feroz, nas relações hierárquicas de cunho exploratório, segregador e que naturalizam a desigualdade. As crianças deveriam, no seu direito à cidade, não apenas conhece-la, mas projeta-la com adultos e adultas visando possibilidades de outras sociedades, outras cidades. Concernente a investigação acadêmica observa-se a presença de metodologias cujas preocupações voltam-se para o encontro dos pontos de vista das crianças. Como é considerar as cidades, em especial as metrópoles, a partir das crianças, desde tenra idade? Desafiadora questão que vamos tentando contornar e aprender buscando faze-lo com a criançada, desde bem pouca idade.

Sabemos com Careri (2016) que caminhar é criar paisagens, ao mesmo tempo, que se trata de ato político problematizador e propositivo. Assim, caminhar cria paisagens e elas são criadas no caminhante de modo concomitante. Com isso, o caminhar desde a infância contribui para a criação de outras paisagens e a diluição da constante presença e pontos de vista adultocentrados que encontramos pelos caminhos percorridos e que se inscrevem em nós. Parques, ruas, avenidas e seus tempos tão aligeirados podem ser questionados. Afinal, quanto tempo temos para a travessia de uma grande avenida? Quem tem ou deveria ter preponderância? Automóveis, adultos, crianças e estas em seus carrinhos de bebês, quem tem o maior tempo e privilégio para usufruir a cidade? Quem deixa suas marcas pelos muros? Por que não também as crianças?

Infelizmente, não posso deixar de observar: que bom Zé Carlos ter feito esse registro fotográfico a nos inspirar a pensar sobre os espaços urbanos de seu bairro e ampliá-los para outras questões referentes à São Paulo. Os mesmos grafites já não existem mais. Eles foram apagados nos primeiros meses do ano de 2017. A memória, contudo, está aqui registrada para provocar a pensar sobre as inscrições numa cidade planejada que deixa suas marcas em todos, vívida e vivida diferentemente por cada um e aqui no registro fotográfico criado por um menino, frequentador de uma EMEI paulistana, fazendo refletir a partir de seus itinerários e suas formas de ver a cidade. Fica o convite para um tempo mais lento em que possamos andar, enxergar com todos, desde as crianças com bem pouca idade. Como diria Caetano, o compositor: gente quer ser feliz, quer durar, quer 
crescer, quer luzir... e que as crianças junto com adultos e adultas possam deixar suas marcas de alegria e luta nos espaços-ambientes públicos democrática e respeitosamente em projetos de cidades menos gris. Vamos olhar para os lados e elas estarão lá.

\section{REFERÊNCIAS}

CARERI, Francesco. Walkscapes: O caminhar como prática estética. Barcelona. Editora Gustavo Gilli, 2016.

CORSARO, Willian. Sociologia da Infância. Porto Alegre, Editora Artmed, 2011.

DELGADO \& MULLER (2011). Educ. Soc., Campinas, vol. 26, n. 91, p. 351-360, Maio/Ago. 2005

FARIAS, RHAISA NAIADE PAEL ; MÜLLER, Fernanda . A Cidade como Espaço da Infância. EDucação e Realidade Edição eletrônica, v. 42, p. 261-282, 2017.

GOBBI, Marcia Aparecida. Desenhos de Outrora, Desenhos de Agora: Mário de Andrade colecionador de desenhos e desenhista. 1. ed. São Paulo: Annablume, 2011. v. 01. 154p

GOBBI, Marcia Aparecida. Em andanças e culturas infantis: as cidades que surgem entre as cidades. In: Jason Ferreira Mafra; Jose Carlos Batista; Ana Maria Haddad Baptista. (Org.). Educação Básica: Concepções e Práticas. 1ed.São Paulo: BT Acadêmica, 2015, v. 01, p. 129-147.

HARVEY, David. Cidades rebeldes: do direito à cidade à revolução urbana. São Paulo, Martins Fontes, 2014.

HIRSCHFELD (2016). Por que os antropólogos não gostam de crianças? Revista Latitude, Vol. 10, nº 2, pp. 171-216, 2016

KOWARICK, Lúcio. 2009. Viver em risco. São Paulo: Editora 34.

KOSSOY, Boris. Fotografia e História. São Paulo. Ateliê Editorial. 2001

LEFEBVRE, Henri (1991a). O direito à cidade. São Paulo, Moraes. (Ed. Documenta, 1969).

SAMAIN, Ettiene (org). Como pensam as imagens. Campinas. Editora da UNICAMP. 2012

TONUCCI, Francesco. La ciudad de los niños. Editora Fundação German Sanchez, 1996. 


\section{ENTRE A CASA, A RUA E A ESCOLA: O QUE O MENINO VIU? ITINERÁRIOS DE UMA CRIANÇA EM SÃO PAULO}

O que um conjunto de fotografias criadas por um menino de cinco anos pode informar sobre a cidade de São Paulo? Essa pergunta orienta a escrita desse artigo que tem como objetivo refletir sobre questões urbanas a partir de conversas e uma sequência fotográfica elaborada por Zé Carlos. Frequentador de uma Escola Municipal de Educação Infantil participou em 2014 de uma pesquisa em que buscávamos imagens de São Paulo segundo o ponto de vista de crianças a partir de escolas públicas de educação infantil, e com isso, conhecer a paulistana cidade em seus conflitos, diferenças e pulsações. Nesse artigo optou-se por um recorte delimitado: um conjunto de fotografias elaboradas por uma única criança num amplo universo de participantes e esse conjugado a falas proferidas junto à pesquisadora. Busca-se provocar debates sobre percepção e formulação do urbano pelas lentes de uma criança, o que pode nos servir para refletir sobre questões e percepções mais abrangentes sobre o viver e morar em São Paulo.

Palavras-chave: Infância, cidade, imagens

\section{BETWEEN THE HOUSE, THE STREET AND THE SCHOOL: WHAT DID THE BOY SEE? ITINERARIES OF A CHILD IN SÃO PAULO}

What can a set of photographs created by a five-year-old boy tell about the city of São Paulo? This question guides the writing of this article that aims to reflect on urban issues from conversations and a photographic sequence elaborated by Zé Carlos. The attendant of a Municipal School of Early Childhood Education participated in a survey in 2014 looking for images of São Paulo according to the point of view of children from public schools of children's education, and with that, to know the city of São Paulo. $n$ this article we opted for a very limited cut: a set of photographs produced by a single child in a wide universe of participants and that conjugated to speeches given to the researcher. It seeks to provoke debates about the perception and formulation of the urban through the lenses of a child, which can serve to reflect on broader issues and perceptions about living and living in São Paulo.

Key words: childhood, images, city

\section{ENTRE LA CASA, LA CALLE Y LA ESCUELA: ¿QUÉ VIO EL NIÑO? ITINERARIOS DE UN NIÑO EN SAN PABLO}

¿Qué un conjunto de fotografías creadas por un niño de cinco años puede informar sobre la ciudad de São Paulo? Esta pregunta orienta la escritura de ese artículo que tiene como objetivo reflexionar sobre cuestiones urbanas a partir de conversaciones y una secuencia fotográfica elaborada por Zé Carlos. Frecuentador de una Escuela Municipal de Educación Infantil participó en el 2014 de una investigación en la que se buscaba imágenes de São Paulo según el punto de vista de niños a partir de escuelas públicas de educación infantil, y con ello, conocer la paulistana ciudad. En ese artículo se optó por un recorte bastante delimitado: un conjunto de fotografías elaboradas por un solo niño en un amplio universo de participantes y ese conjugado a las palabras pronunciadas ante la investigadora. Se busca provocar debates sobre percepción y formulación de lo urbano por las lentes de un niño, lo que puede servirnos para reflexionar sobre cuestiones y percepciones más amplias sobre el vivir y vivir en São Paulo.

Palabras clave: niños, imagenes, ciudad 